\title{
Homenagem ao Prof. Paulo Fraletti
}

\section{Tribute to Prof. Paul Fraletti}

\section{José Cássio Simões Vieira ${ }^{1}$, Alexandrina Silva Meleiro², Arthur Guerra de Andrade³, Francisco Lotufo Neto ${ }^{4}$, Wagner Farid GattaZ ${ }^{5}$, TÁKI Athanássios CoRdÁs 6}

\author{
Ex-professor da Faculdade de Medicina do ABC (FMABC). \\ 2 Doutora em Psiquiatria. \\ 3 Titular de Psiquiatria e Psicologia Médica da Faculdade de Medicina do ABC (FMABC) e professor-associado do Departamento de Psiquiatria da Faculdade de Medicina da Universidade de São \\ Paulo (FMUSP). \\ ${ }^{4}$ Departamento de Psiquiatria da Faculdade de Medicina da Universidade de São Paulo (FMUSP). \\ 5 Titular do Departamento de Psiquiatria da FMUSP. \\ ${ }^{6}$ Coordenador-geral do Ambulatório de Bulimia e Transtornos Alimentares (Ambulim) do Instituto de Psiquiatria do Hospital das Clínicas da FMUSP, professor-colaborador do Departamento de \\ Psiquiatria da FMUSP, professor do Programa de Pós-Graduação do Departamento de Psiquiatria da FMUSP e do Programa de Neurociências e Comportamento do Instituto de Psicologia da USP.
}

Recebido: 17/1/2011 - Aceito: 31/1/2011

Vieira JCS, et al. / Rev Psiq Clín. 2011;38(1):1-2

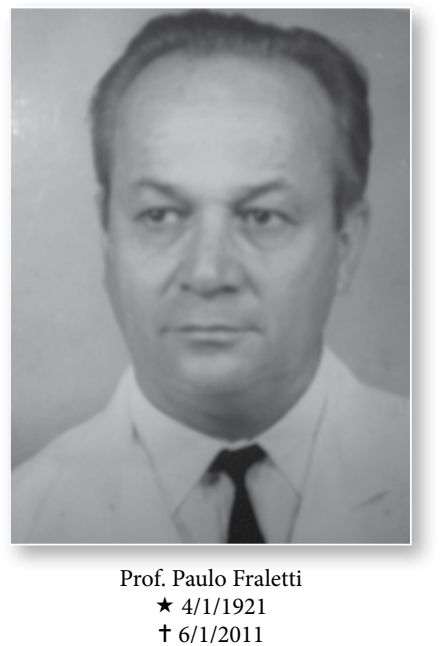

Poucos dias após haver atingido a glória de seus 90 anos, em 6 de janeiro, faleceu o Prof. Paulo Fraletti, psiquiatra de Escol e mestre de inúmeras gerações de especialistas ligados a atividades docentes.

Nasceu em Pereiras (SP), em 4 de janeiro de 1921. Fez o curso primário em sua terra natal, o secundário em São Paulo, no Liceu Coração de Jesus, e o superior, médico, três anos em Curitiba e três anos na capital de São Paulo, na Escola Paulista de Medicina, pela qual se diplomou em 1947. Foi, no tempo de acadêmico, diretor e redator de O Bíceps, órgão dos alunos da Escola Paulista de Medicina. Desse tempo, foi considerado pelos seus contemporâneos como memorável, por ocasião de sua formatura, seu discurso "Vocação Hipocrática" como o orador da turma.

Exerceu a psiquiatria como médico da Secretaria da Saúde, no Manicômio Judiciário do Estado de São Paulo e no Departamento Psiquiátrico II (Franco da Rocha), de 1948 a 1990, quando se aposentou. Foi diretor do Manicômio (hoje, Hospital de Custódia e Tratamento Psiquiátrico), de 1963 a 1971, e diretor-geral do Núcleo Hospitalar de Juqueri, de janeiro de 1972 a março de 1973.

Trabalhou também em sua clínica particular em Psiquiatria Clínica Forense durante 48 anos, de 1948 a 1996, em São Paulo, e concomitantemente, em períodos especiais, em Sorocaba, Taubaté e Santo André, bem como em Pereiras, aos sábados e domingos, feriados e férias, desde a formatura até data recente, graciosamente nesta última.
Foi professor de Psiquiatria e Psicologia Médica na Faculdade de Medicina de Sorocaba, da PUC-SP ( 9 anos), na de Taubaté (5 anos), na de Ciências Médicas da Santa Casa de Misericórdia de São Paulo (5 anos) e na de Medicina, da Fundação Universitária do ABC (23 anos), da qual se tornou professor emérito. Das duas primeiras, foi professor cofundador, bem como lecionou nas Escolas de Enfermagem do Juqueri (em Franco da Rocha) e do Hospital São Paulo (na capital) e no curso de Psicologia do Trabalho, da Faculdade de Filosofia, Ciências e Letras de São Bento, da PUC-SP.

Paralelamente à medicina, dedicou-se à literatura e ao jornalismo como historiador, poeta, orador e conferencista, com inúmeros trabalhos médico-científicos publicados, individual e conjuntamente, além de sete livros de poesia e trabalhos vários esparsos.

Dirigiu as revistas Arquivos da Coordenadoria de Saúde Mental, Boletim Mensal do Centro de Estudos Franco da Rocha e Boletim de Higiene Mental, além de ter fundado e editado, em sua cidade, cinco jornais e uma revista.

Foi membro de inúmeras sociedades médicas, psiquiátricas e culturais, como a Associação Paulista de Medicina (São Paulo), depois da Regional de Piracicaba, da Academia Paranaense de Letras (membro correspondente), do Instituto Histórico e Geográfico de São Paulo, do Instituto Histórico Geográfico e Genealógico de Sorocaba, do Clube dos Escritores de Piracicaba e das Academias de Letras de Sorocaba e de Piracicaba e muitas outras. Foi membro do 
Conselho Regional de Medicina de São Paulo (Cremesp), além de ter fundado em Pereiras o Museu-Arquivo Pereirense e a Associação Pereirense de Cultura, Recreação e Assistência. Criou também o Centro Histórico-Cultural de Pereiras.

Foi agraciado com a Comenda Marechal Rondon, da Sociedade Geográfica Brasileira, e a Medalha Cultural Aluísio de Almeida, do Instituto Histórico, Geográfico e Genealógico de Sorocaba. Dentre as inúmeras sociedades médicas, psiquiátricas e culturais, é membro da Sociedade Brasileira de Médicos e Escritores.

Sempre lembrado por todos que tiveram a satisfação de terem sido seus alunos e colaboradores pela enorme disposição para discutir, esclarecer e, principalmente, ensinar. Chegava a se esquecer da hora fora da sala de aula ou da rotina hospitalar, em detrimento de seu descanso, quando começava a contar casos e experiências vividas, prendendo a atenção dos empolgados ouvintes.

Polêmico e muitas vezes irreverente, defendia com muita propriedade seus pontos de vista, o que ressaltava a firmeza de suas convicções e a eficiência de suas atuações profissionais, sempre alicerçadas nos princípios éticos.

No ambiente universitário, o Prof. Paulo Fraletti apresentava-se de maneira bastante peculiar. Dono de uma didática impressionante, seguia um modelo hoje criticado pela moderna pedagogia: dava uma aula teórica de cerca de 2 horas utilizando apenas giz e lousa. Abordava os principais temas da Psiquiatria e da Psicologia Médica tendo como referência uma série de papéis que lhe serviam de roteiro e, de forma absolutamente espetacular, inseria diferentes exemplos tanto da sua clínica particular como especialmente de pessoas que estavam no noticiário recente. Não raro, no final dessas vinhetas, a turma de alunos se manifestava seja com sorrisos, com emoções e com pequenos comentários. $\mathrm{O}$ professor não tinha pruridos para apresentar suas ideias, algumas vezes temperadas com bom humor, sempre respaldadas na ética, no bom-senso e no respeito, tanto com os pacientes como com seus familiares. $\mathrm{O}$ efeito dessa didática era fabuloso: a turma de cem alunos ficava intensamente envolvida em suas aulas e, mesmo muitos anos depois de graduados, vários alunos, hoje médicos, ainda se lembram dos exemplos vivos que o professor dava. Seu foco eram os alunos que não iriam fazer da psiquiatria sua especialidade. Nesse cenário era natural que alguns poucos alunos discordassem dos exemplos e das posturas do professor. Quase sempre esses alunos eram recebidos com carinho e respeito pelo professor, que, sem abrir mão das suas posições, ouvia e rebatia as opiniões contrárias.

Não só por essas qualidades, o professor foi diversas vezes homenageado por diferentes turmas de alunos, seja como paraninfo ou como patrono. Por onde passou, deixou muitos ensinamentos e, sobretudo, muitas saudades.
Dono de uma cultura extraordinária, médica e humanística, era um grande estudioso da especialidade, especialmente da Escola Alemã de Psiquiatria, familiarizando seus alunos com Jaspers, K. Schneider, Griesinger, Kretschmer, numa época em que em geral os cursos de psiquiatria negligenciavam os fundamentos da especialidade.

Crítico da psicanálise, sempre lúcido na defesa de suas argumentações, era, no entanto, grande admirador e conhecedor da obra do psicanalista austríaco Wilhelm Stekel, que, embora considerado pelo próprio Freud como um de seus mais brilhantes discípulos, tem sua obra ainda pouco conhecida.

O professor Fraletti dizia sempre que a semiologia e a psicopatologia nos ensinam a conhecer a doença e as obras literárias, a conhecer o doente, exigindo de seus discípulos e alunos o cultivo da cultura literária.

Destacamos alguns de seus ex-discípulos e ex-colaboradores que muito enriqueceram seus conhecimentos hauridos na convivência com o professor Fraletti e que agora formam novos especialistas: Wagner Farid Gattaz (titular do Departamento de Psiquiatria da Faculdade de Medicina da Universidade de São Paulo - FMUSP), Arthur Guerra de Andrade (titular de Psiquiatria e Psicologia Médica da Faculdade de Medicina do ABC - FMABC - e professor-associado do Departamento de Psiquiatria da FMUSP), Jair de Jesus Mari (titular do Departamento de Psiquiatria da Universidade Federal de São Paulo - Unifesp), Francisco Assumpção Batista, Francisco Lotufo Neto, Táki Athanássios Cordás, Alexandrina M. A. Silva Meleiro, Salvador Rossi, Sonia Sampaio Duarte, Sergio Baldassin, Rafael Villanacci, Eva Helena Zoppe, José Cássio Simões Vieira, Roberto Bataglia Theodoro, José Américo dos Santos, Antônio José Eça, Guido Arthuro Palomba, José Luiz Pacheco, Sérgio Traldi, e muitos outros.

Diante da tristeza de sua partida, nosso consolo é que nem tudo finda com a morte. $\mathrm{O}$ concurso direto que resulta de uma valorosa existência, que formou brilhantemente uma elite de médicos psiquiatras, não desaparece com esta - a colaboração indireta, decorrente do cultivo de uma memória querida, perdurará para sempre.

De seus ex-alunos:

José Cássio Simões Vieira Alexandrina Silva Meleiro Arthur Guerra de Andrade Francisco Lotufo Neto Wagner Farid Gattaz Táki Athanássios Cordás 